\title{
O pensamento criativo de Paul Klee: arte e música na constituição da Teoria da Forma
}

\author{
Rosana Costa Ramalho de Castro (UFRJ /UFF, Rio de Janeiro, RJ) \\ rosana.r.c@terra.com.br
}

\begin{abstract}
Resumo: Estudo sobre a Teoria da Forma concebida no início do século XX pelo artista plástico Paul Klee e publicado no livro 0 Pensamento Criativo (KLEE, 1920). A Teoria da Forma de Paul Klee é uma demonstração do pensamento artístico que adota pressupostos formais, previamente estabelecidos para resultar na prática da representação artística. Klee identificou as relações formais entre a música e as artes visuais, apresentando conexões entre a linha melódica e a linha no desenho; o ritmo e as seqüências de módulos e sub-módulos; os tempos dos compassos e as divisões da pintura; a métrica da música e a modulação da forma e da cor nas artes visuais. Klee também apresentou suas experiências com superposição de cores e texturas para representar visualmente a polifonia. A Teoria da Forma de Paul Klee é um exemplo de estudo que pressupõe modelos formais para a elaboração artística e projetual.
\end{abstract}

Palavras-chave: Paul Klee, arte e música, Teoria da Forma, análise de imagens, metodologia visual.

\section{The creative thinking of Paul Klee: art and music in the formation of the Theory of Form}

Abstract: Study on the Theory of Form conceived in the early twentieth century by artist Paul Klee and published in the book The Creative Thinking (KLEE, 1920). The Theory of Form of Paul Klee is a demonstration of an artistic thought that adopts the previously established formal prerequisites that result in the practice of artistic representation. Klee identified the formal relationship between music and the visual arts, providing connections between the melodic line and the line in the drawing, rhythm and sequence of modules and sub-modules, the pulses of the measures and the divisions of the painting, metrics in music and the modulation of shape and color in the visual arts. Klee also presented his experiences with overlapping colors and textures to visually represent polyphony. The Theory of Form of Paul Klee is an example of a study that requires formal models for the artistic and design elaboration.

Keywords: Paul Klee, art and music, Theory of Form, image analysis, visual methodology.

\section{1 - Introdução}

Nascido na Suiça em 1879, Paul Klee foi um dos principais teóricos do movimento construtivista nas artes plásticas. Sua obra tornou-se importante para a fundamentação do construtivismo alemão, contribuindo para sedimentar o pensamento formalista adotado pela Bauhaus, na Alemanha da década de 1920.

Educado numa família de músicos, Klee demonstrava desde jovem seu interesse na existência de uma relação formal entre a música e as artes visuais. Por isso, desde os primeiros anos de sua vida escolar já realizava experimentos neste sentido, desenhando os códigos simbólicos do universo da música nas bordas dos cadernos de aulas de desenho geométrico. Em 1898, com 19 anos de idade, seu aprendizado do desenho era acompanhado de representações da escritura musical. Enquanto aprendia a desenhar uma elipse, Paul Klee via, na forma geométrica, o olhar de Beethoven. A imagem abaixo faz parte dos cadernos de estudos do artista. 


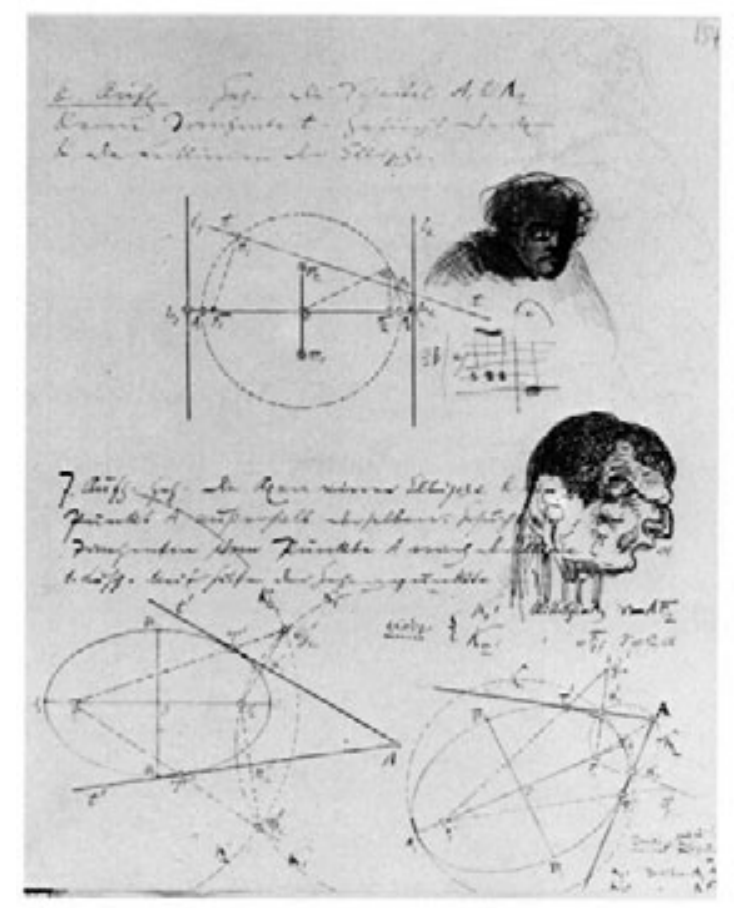

Ex.1 - Paul Klee, O Olho de Beethoven do caderno escolar de geometria analítica do artista. Felix Klee, Berna, 1898, p.154; caneta, tinta e lápis, 23 × 18,5 cm.

Além do reconhecimento como artista e teórico das artes visuais e um dos principais mestres da Bauhaus (DROSTE, 1994), Paul Klee também foi reconhecido como músico, chegando a fazer parte, como violinista, da Orquestra Municipal de Berna, além de participar de outros grupos musicais (MARÇAL, 2009).

Talvez pela experiência nos dois segmentos das artes, Klee se debruçara nos estudos que despertavam o interesse de vários artistas da época. No período compreendido entre 1850 e 1950, artistas de várias tendências realizavam experiências similares. Dentre eles, nomeamos alguns importantes pintores e teóricos das artes: Delacroix, Ruskin, Gauguin, Seurrat, Delaunay, Kandinsky, Matisse, Tobey, Mondrian e Pollock. Todos eles procuravam representar no quadro, alguns em textos escritos, as possibilidades de existir inter-relação entre as artes visuais e a música, mas nenhum deles dedicou tanto tempo e energia para elaborar uma teoria extensa que justificasse as experiências visuais representando os valores do compasso, dos tempos musicais, das divisões dos tempos, das notas em seqüências com diferentes valores de tempo e, na essência disso tudo, revelando a manifestação convicta de seu pensamento filosófico sobre a dualidade, do caos ao cosmos, refletido sobre os opostos: o silêncio necessário ao som; na forma inexistente sem seu complemento que é o fundo; no claro contraposto ao escuro e no movimento como modo de interação entre estes opostos.

Talvez o conhecimento adquirido nas duas linguagens artísticas tenha sido o estímulo para desenvolver teoricamente a idéia filosófica que o acompanhava, porque por um período relativo à $2 / 3$ de sua vida Klee realizou pesquisas no âmbito da pintura e do desenho e elaborando, em paralelo, as teorias sobre o pensamento criativo. A tônica de suas pesquisas evidenciava a relação entre a arte pictórica e a música. Assim, dizia ele a respeito da temporalidade existente na pintura:

\begin{abstract}
Cada vez mais estou convencido acerca dos paralelismos entre a música e a arte (...) Sem dúvida ambos são temporais, o que é fácil de demonstrar... os movimentos expressivos do pincel, a gênese do efeito. (Wick apud KLEE, 1990,320)
\end{abstract}

Mas, apesar de parecer despertar um interesse meramente formal, Klee destinava seus experimentos para formalizar a idéia de que a representação do movimento levava à dimensão filosófica da existência e do mundo. Ao abordar conceitos de natureza puramente plástica, principalmente a questão da estrutura do quadro, revia a lei do movimento. Ao postular a harmonia plástica, desenvolvia a noção do equilibrio entre o 'princípio fundamental masculino' e o 'princípio fundamental feminino' (KLEE,1973), entre o espírito e a matéria. Para isso, utilizava a imagem do pêndulo como meio de designar as forças opostas e formadoras do universo. E a música era a essência dessas forças, pois utilizava os opostos: som e silêncio pela realização em desenvolvimento, nunca na obra finalizada. Para ele, o processo de formação do universo: do caos à ordem, deveria ser o principio formador da arte. E assim dizia a respeito: [...] não pensar na forma mas na formação: interessam mais as forças formadoras do que as formas finais. (Wick apud KLEE, 1990)

Valorizando a realização, Klee, considerava uma obra finalizada como o encerramento de um processo conceptivo, culminando nela própria. No entanto, para ele, haveria um processo temporal até mesmo no ato de pintar, vinculando-o ao movimento físico desenvolvido pelo artista durante o processo de realização da obra. E não apenas neste caminho, também na existência dos pressupostos formadores da obra se encontravam um preexistente que também seria dado em contínuo na obra seguinte, ou seja: a partir da elaboração dos conceitos pressupostos formais que alinhavavam a concepção da obra pictórica aos valores formais da música haveria um contínuo movimento para a concepção da obra por vir.

Apesar do empenho em resolver as questões formais, da estrutura e composição do quadro, Klee pretendia alcançar mais além, como poderemos compreender por suas palavras apresentadas a seguir:

Somos artistas, homens práticos de ação, razão pela qual atuamos, por natureza, em um âmbito preferencialmente formal. Sem esquecer que antes do inicio formal, ou mais simplesmente antes do primeiro traço, existe uma história precedente, e não apenas o anseio, o prazer do homem em se expressar, não apenas a necessidade exterior de fazê-lo, mas também um estado geral de sua condição humana cuja direção recebe o nome de visão de mundo e que surge aqui e acolá com a necessidade interior de manifestar-se. Faço questão de frisar isso para que não se produza o mal entendido de que uma obra se compõe apenas de forma. (Wick apud KLEE, 1990) 
A partir de 1919, já reconhecido no meio artístico, Klee fora convidado por Gropius para participar do corpo docente da Bauhaus, instituição de ensino artístico destinado a formar profissionais nas áreas da arquitetura e do design. A partir de então, Klee passou a lecionar e pintar em seu atelier localizado nas dependências da Instituição, enquanto dava andamento aos seus escritos que chegaram a somar mais de 3000 páginas.

E, a partir de 1920, sua obra teórica passou a ser publicada. No Pensamento Criativo, nome as obra teórica onde Klee apresenta as bases de seu pensamento, encontramos a elaboração dos pressupostos formais que são relacionados com a escritura musical, servindo como base do processo criativo construtivista. Estes estudos são legados importantes, apesar de representarem um segmento das artes e do design baseados no formalismo que, na atualidade, é motivo de discussões. Ainda se encontram nas escolas artísticas mais tradicionais dedicadas ao ensino da arte, do design e da comunicação visual, os mesmos elementos pressupostos, apesar de não serem detalhadas as relações com a escrita musical. Sendo publicada na época em que Paul Klee lecionava na Bauhaus, sua obra teórica tornou-se fundamental para a constituição da Teoria da Forma adotada naquela instituição de ensino, daí, ainda hoje é aceita e adotada na disciplina de Metodologia Visual, fomentando o pensamento formalista.

0 desenvolvimento do trabalho teórico de Paul Klee devese ao incentivo de Walter Gropius, fundador e diretor da Bauhaus, que se interessava pelas pesquisas formais no campo da linguagem universal das artes. Neste sentido, Gropius não só contribuiu para sacramentar o pensamento de Klee, incentivando o entrelaçamento entre o trabaIho dos ateliers com as aulas teóricas na Bauhaus como também de vários professores da instituição, como Kandinsky, outro importante artista que teorizava sobre seus procedimentos criativos, publicando vários livros tratando deste assunto (KANDINSKY 1987, 1989, 1990), além de pintar vários quadros que imaginava serem transposições dos efeitos musicais para suas pinturas. Enquanto Klee procurava desenvolver um trabalho lógico, construtivista, Kandinsky buscava a interação espiritual através da pintura expressionista.

\section{2 - 0 pensamento criativo de Paul Klee}

A obra teórica de Klee é, provavelmente, o marco inaugural das artes abstratas do campo geométrico. No entanto, mais do que isto, sua proposta inaugurava uma nova vertente para o ato criativo das artes visuais, pois revelava um procedimento mental distinto, iniciando pelos alicerces filosóficos dos quais emergiam os pressupostos formais teóricos e metodológicos. Ao escrever a respeito, Klee elaborou um arcabouço metodológico consistente e singular, como veremos a seguir.

Apresentaremos alguns resultados dos estudos formais de Klee da obra: La Pensée Creatice. Écrits sur L'Art / 1, incluindo textos recolhidos e anotados por Jurg Spiller, publicada em edição pela Dessais et Tolra em 1973. Ali encontramos propostas do autor com desenhos e textos que procuram demonstrar de modo claro e objetivo os caminhos seguidos para a constituição da Teoria da Forma.

De início, ele apresenta a base filosófica de seu pensamento, na idéia de dualismo, não apenas dos opostos, mas, inclusive, do ponto intermediário: o ponto "gris" como intermediário entre os opostos: caos e cosmos. Segundo refere-se o autor: "Eu inicio pelo caos, é a maneira mais lógica e a mais natural. Eu não me preocupo, pois posso me considerar em primeiro lugar como o caos." (KLEE,1973,9).

A mesma noção de dualidade percebida no pensamento de Klee é parte dos questionamentos filosóficos desde Platão. 0 cosmos grego resulta da sintese de dois princípios opostos: as idéias e a realidade cotidiana. Segundo o filósofo Platão, o princípio de movimento e de ordem revela o conhecimento do mundo que nos cerca: o ser (as idéias) e o não-ser (a realidade cotidiana) (TARNAS, 2008). 0 dualismo dos elementos constitutivos do mundo material resulta da ordem e da desordem, do bem e do mal.

A imagem de dualidade está presente, também, no pensamento de outros filósofos e destacamos o de Descartes, filósofo do século XVII que influenciou, e ainda influencia, o pensamento ocidental moderno e da atualidade (TARNAS, 2008). No dualismo de Descartes, mente e corpo são substâncias distintas. À mente aproxima-se conceitos de intelecto, de pensamento, de entendimento e de alma do ser humano, sendo o outro ponto do dualismo referente ao corpo. As duas substâncias: res cogitans ou res extensa (KAMPER, 2008), mente e corpo, são distintas, de naturezas irredutíveis. Na visão de Kamper, o corpo reclama a não existência em relação à mente, e reage na atualidade desprezando a própria idéia preconcebida de corpo como extensão da mente.

0 valor da imagem dual vai aparecer na filosofia antiga e contemporânea, e também nos estudos da lingüística, da semiologia, enfim, em vários princípios teóricos, filosóficos e em diferentes pensamentos.

Podemos refletir melhor a respeito do pensamento dual de Klee ao ler suas próprias palavras:

Nós dispomos, a partir dai, de duas energias: uma ofensiva e outra defensiva que se sucedem ou se mesclam. Nós temos a tarefa dificil de estabelecer um equilibrio vivo entre estes dois pólos; significação profunda da interpretação natural a partir da base de referência negro, branco, noção de equilibrio antitético. (KLEE, 1973,10)

Seguindo sua idéia, o ponto "gris" induz ao movimento cósmico e, por este ponto, espraiem-se os opostos que pertencem à natureza dual de todas as coisas. Caos e cosmos são representações máximas destes opostos e 0 ponto denominado 'gris' é o lugar onde se encontra a 'ausência absoluta' dos opostos: a tênue membrana de limite dos opostos. Este ponto, segundo Klee, é caracterizado pela ausência de contraste. 
Em termos objetivos, Klee propõe que seja considerada a existência do duplo (de um no seu oposto, o outro). Assim, o alto só tem existência a partir da comparação com seu oposto: o baixo; o mesmo sentido existencial ocorrendo entre o frio e o quente; o feminino e o masculino; o claro e o escuro etc.

A natureza dual das coisas é expressa na realidade, que enfoca o conhecimento de um pelo que não está contido no outro. Sem um não é possivel compreendermos o outro. Não podemos compreender, por exemplo, o som sem sua relação com o silêncio. Também, no âmbito das artes visuais, a percepção da forma depende da existência do fundo e vice-versa.

A partir destas considerações, podemos entender as bases filosóficas que emergem no pensamento de Klee e seguem para além: do dualismo à constituição do objeto metodológico, criativo, dos pressupostos formais que são comuns no ponto de ligação entre a visualidade e a musicalidade, no mesmo ponto que mescla os extremos e demanda a criação musical e também a composição visual. Em termos práticos, quando se refere à visualidade, Klee destaca a idéia de movimento contido na percepção de um (fundo) e de outro (forma) (ARNHEIM,1986), gerando um movimento constante e oscilatório. Assim também ocorre de um (o som) e de outro (o silêncio), que são os componentes básicos da música.

Em seguida, apresentaremos os primeiros passos realizados por Paul Klee para elaboração da Teoria da Forma. As páginas do caderno apresentam desenhos esquemáticos e informações escritas identificando linhas esquemáticas de linhas melódicas.

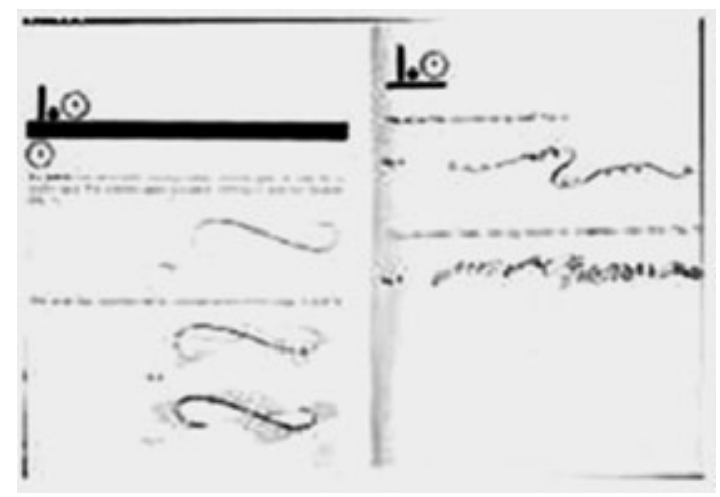

Ex.2 - Paul Klee, Cadernos Pedagógicos. Introdução e Tradução de Moholy-Nagly.

Plano inicial para Ensino Teórico da Bauhaus alemã. Ed. Frederick A. Praedger, NY, 1953.

A representação acima é seguida de vários exemplos gráficos de movimento, linha melódica, e outras grafias relacionadas à música. Nosso trabalho, a seguir, é explicitar estes elementos iniciando pelo ponto, elemento mínimo da composição plástica. Para Klee o ponto não é sem dimensão, mas sim executa o movimento zero (KLEE,1973).

Tratando da tensão existente entre um ponto e outro, ele entende a linha que tanto pode ser reta como curva, ou

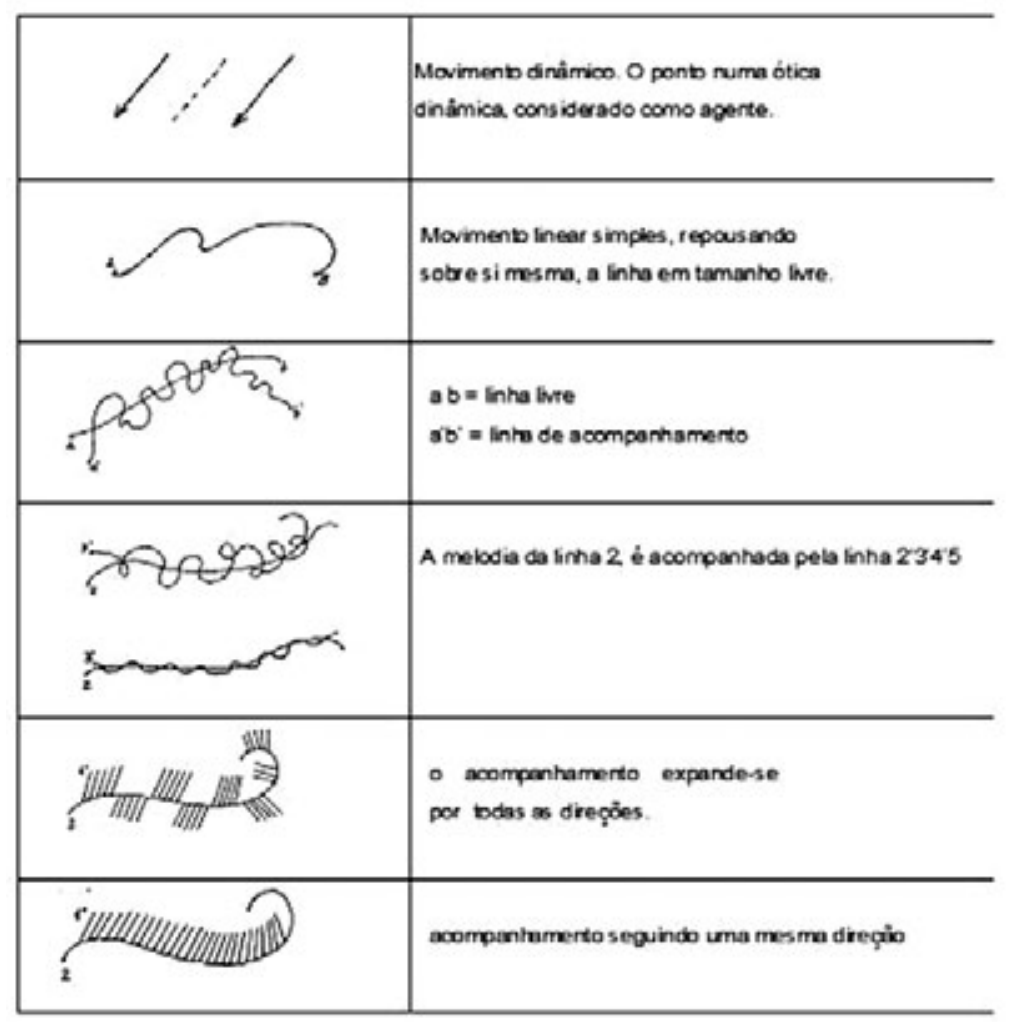

Ex. 3 - Tabela de desenhos propostos por Paul Klee em correspondência aos textos, copiados de sua obra La Pensée Créatrice. 
ainda sinuosa, ou, quem sabe, até angulosa. A seqüência de pontos descreve uma linha que é a trajetória de um movimento. Isto ocorre também na música, quando uma seqüência de notas determina uma linha musical. Klee quer compreender a linha pela possibilidade de gerar movimento. Ele vê na seqüência de pontos exatamente o que ocorre também na linha melódica: a seqüência de notas determina a trajetória da linha melódica.

Esta linha é denominada por Klee de linha ativa (KLEE, 1973,105), pois executa um movimento perfeitamente espontâneo (KLEE,1973). Na seqüência de desenhos podemos observar de que maneira Klee representa a linha ativa. As ilustrações estão aqui reproduzidas e seguem com as explicações do próprio autor.

Os desenhos a seguir também são cópias da obra do autor e demonstram outros tipos de linhas e as similaridades entre os movimentos oscilatórios e a linha musical.
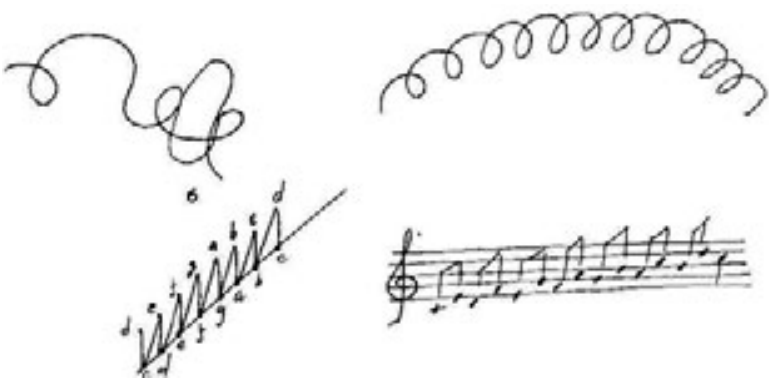

Ex.4- Desenhando a duas vozes, notas de Paul Klee para os Cursos da Bauhaus. Paul Klee Foundation, Kunstmuseum, Bern.

Linhas melódicas, contrapontos, harmonias, estão correlacionados com linhas contínuas do desenho, linhas contrapostas também do desenho e tonalidades harmônicas. Mas, sobretudo quando ele conceitua o ponto e a linha, contrapõe à nota musical, à linha melódica, aos tempos rítmicos e passa a representar o movimento no espaço bidimensional. Assim, Klee sistematiza a concepção do compasso na existência de uma estrutura de malha de construção, formada por linhas horizontais e verticais para construir estruturadamente o espaço bidimensional similar ao universo musical. Estas linhas, quando superpostas, vão formar módulos quadrados ou retangulares e serão por estes módulos que surgirá a relação entre a linha melódica e construção formal do quadro; a divisão de ritmo e a subdivisão do módulo estabelecendo definitivamente a relação entre as divisões do espaço bidimensional e o compasso musical. Neste sistema, Klee compreende como uma [...] estrutura é uma articulação dividual (KLEE,1973,207) e permite subdivisões proporcionando intenção rítmica. As subdivisões dos módulos na estrutura encontram similaridades na divisão rítmica dos compassos e a utilização modular de cada tempo do compasso encontra paralelo na subdivisão modular do quadro.
Assim, Klee facilita a compreensão desses conceitos, iniciando por definir os 'ritmos estruturais primitivos' formados pelas linhas horizontais e verticais. Este é o primeiro passo para a formação dos quadrados mágicos.

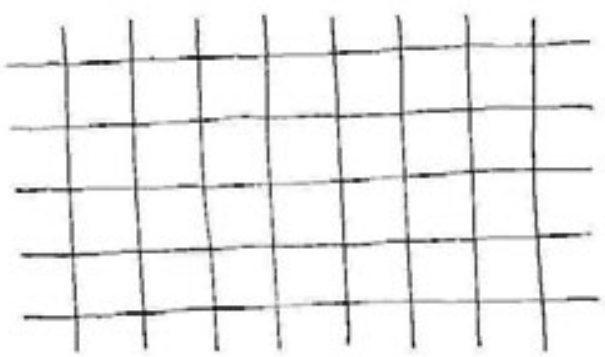

Ex.5 - Paul Klee: exemplo de uma malha em quadrados constituídos a partir da composição de linhas horizontais e verticais.

$\mathrm{Na}$ imagem a seguir, apresentamos a malha de construção e, ao lado, uma pauta musical, com as subdivisões de um compasso quaternário.
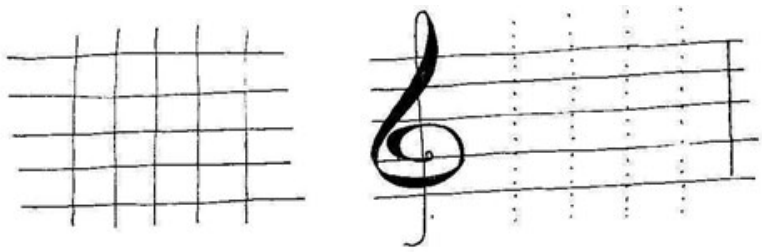

Ex.6 - Paul Klee: exemplo comparativo de malha de construção com módulos quadrados e, ao lado, uma pauta musical de um compasso quaternário com as divisões dos tempos.

Os ritmos estruturais representam o primeiro passo para elaborar a estrutura do quadro. Por eles, formase o sistema das composições pictóricas com divisões geométricas do espaço bidimensional. Em paralelo, na escritura musical os tempos do compasso podem ser subdivididos para atenderem às necessidades rítmicas da obra musical. E esta subdivisão sempre ocorrerá de modo a proporcionar valores modulares e correspondentes ao tempo definido pelo compositor, como uma semínima numa composição de compasso 4/ 4 corresponderá a uma unidade de tempo, enquanto, se o autor desejar que este tempo seja subdividido, possibilitando com isto valores rítmicos diferenciados, ele estará utilizando duas colcheias ou quatro semicolcheias etc. que ocuparão o mesmo tempo da semínima. E na pintura, o valor modular poderá ser subdividido proporcionando meios de valorizar a composição pictórica.

Os desenhos apresentados a seguir demonstram correspondências com a divisão modular pictórica. Comparativamente, o quadrado da esquerda corresponderá a uma semínima, os dois retângulos a duas colcheias etc. 

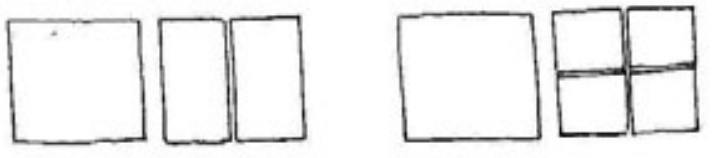

Ex.7 - Paul Klee, módulos quadrados divididos em dois retângulos e em quatro quadrados: correspondências com a escrita musical.

A partir da constituição de uma rede modular, Klee sugeriria várias possibilidades de malhas estruturais. Estas malhas atenderiam às necessidades de composições harmônicas. Klee propõe dois modelos de malhas construção estruturais: estruturas sem alternância' (KLEE,1973) e estruturas com alternância (KLEE,1973). Ainda hoje, o design e a comunicação visual fazem uso dessas estruturas no ensino e na formação do pensamento destinado à concepção de produtos e de imagens de identidade, entre outras aplicações.

Prosseguindo na apresentação da obra teórica, Klee trata da divisão do compasso - do tempo musical - e estabelece a relação que a divisão da linguagem visual. Chamando de ritmos culturais (KLEE,1973) ao sistema de divisão de um módulo em partes, ele determina uma unidade de medida, podendo ser relacionada ao compasso da música. Quando Klee trata da divisão do módulo a partir de uma norma bivalente ou medida a dois tempos (KLEE,1973) podemos compreender as similaridades entre este sistema e um compasso binário. 0 desenho a seguir demonstra visualmente o proposto:

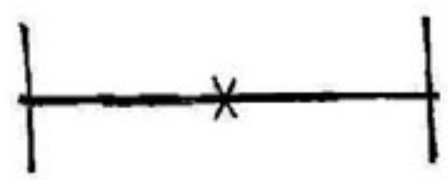

Ex.8 - Paul Klee: uma linha dividida em duas medidas iguais e acompanhando a proposição de Klee para a norma bivalente ou medida a dois tempos.

Quando ele nomeia de norma bivalente está estabelecendo que este segmento seja pertencente a um sistema cuja unidade de medida é um elemento modular e que, por sua vez, subdivide-se em duas partes iguais. Ao chamar este sistema de 'norma bivalente ou medida a dois tempos' está determinando que esta medida possa ser espacial ou temporal. Como podemos constatar no esquema apresentado, trata-se de um segmento de reta que é tratado também como medida de tempo.

0 mesmo pensamento referente à divisão binária também é adotado para as outras divisões, assim como a norma trivalente ou medida a três tempos (KLEE,1973).

Poderemos observar no desenho a seguir o que representa a divisão de uma unidade modular em três partes iguais.

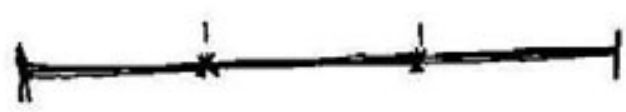

Ex.9 - Paul Klee: uma linha dividida em três medidas iguais e acompanhando a proposição de Klee para a norma trivalente ou medida a três tempos.

Obedecendo ao mesmo critério, percebe-se também que há similaridade entre esta divisão e o compasso ternário. 0 desenho abaixo demonstra as equivalências entre os tempos do compasso ternário e a divisão da linha em três partes:

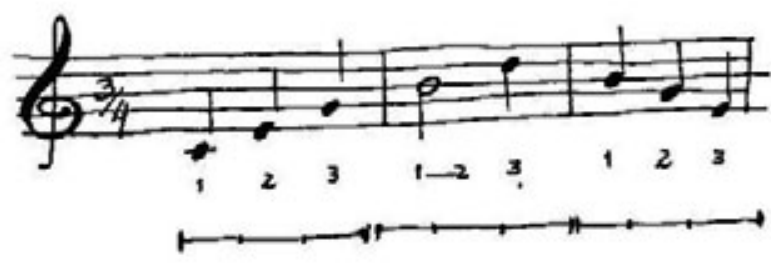

Ex10: Paul Klee: uma pauta musical apresentando um compasso ternário e, logo abaixo, a equivalência na linha visual sub-dividida em três medidas iguais.

Klee propõe variantes para as normas. Para a norma bivalente ou medida a dois tempos, é possivel desenvolver uma variante que seria de uma medida a dois tempos a qual se ajusta uma dupla divisão, resultando numa medida a quatro tempos, como podemos constatar no desenho a seguir:

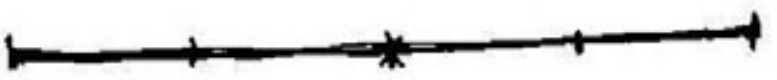

Ex11: Paul Klee: representação da norma bivalente com variante de medida em dois tempos.

Nesta variante, o módulo de medida é subdividido em duas unidades iguais que, por sua vez, abriga subdivisões, resultando num módulo subdividido em quatro partes iguais. Outra variante é a variante da norma bivalente com tripla divisão resultando numa medida a três tempos (KLEE,1973). Nesta variante, o módulo de medida é subdividido em duas unidades e cada uma dessas unidades é subdividida em três partes iguais.

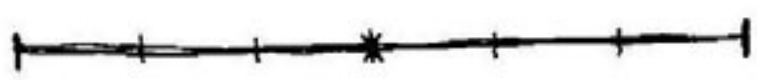

Ex12: Paul Klee: representação da norma bivalente com variante de medida em três tempos.

Ao compararmos com a escrita musical vamos compreender que nesta norma está correlacionada à divisão do módulo, unidade de medida, com um compasso binário composto. Neste tipo de compasso, a unidade de tempo é dividida em dois tempos iguais e subdividida em três tempos, em cada unidade de tempo. 
Ainda em outra proposta, Klee apresenta a variante da norma trivalente com tripla divisão, resultando numa medida a nove tempos (KLEE, 1973).

Apresentamos até o momento apenas alguns modelos propostos por Klee para estabelecer a relação entre as artes visuais e a divisão do compasso, a linha melódica, os valores musicais. A seguir, apresentaremos algumas imagens que demonstram não só a aplicação da Teoria da Forma de Klee e também os primeiros exemplos do pensamento correlacionado.

\section{3 - Primeiras experiências pictóricas}

As primeiras experiências realizadas por Paul Klee relacionando a música com as artes visuais ocorreram nas obras satíricas, utilizando a técnica da gravura. Na obra realizada em 1909 representa a crítica às músicas modernas daquela época. Na grafia da música que se encontra apoiada sobre a estante do piano, há uma série de signos indescritiveis e, no trajeto do trato alimentar da figura que executa a peça musical, há pequenos pontos que se avolumam até alcançarem o local em que o pianista está sentado: um penico. $A$ imagem representa o efeito da peça musical no próprio pianista que a executa. Na representação, há tantas notas a serem dedilhadas que é necessário o uso de duas manivelas, fixadas aos pés do pianista, para que possam auxiliar na interpretação das notas mais graves e nas mais agudas. Podemos observar a gravura a seguir:

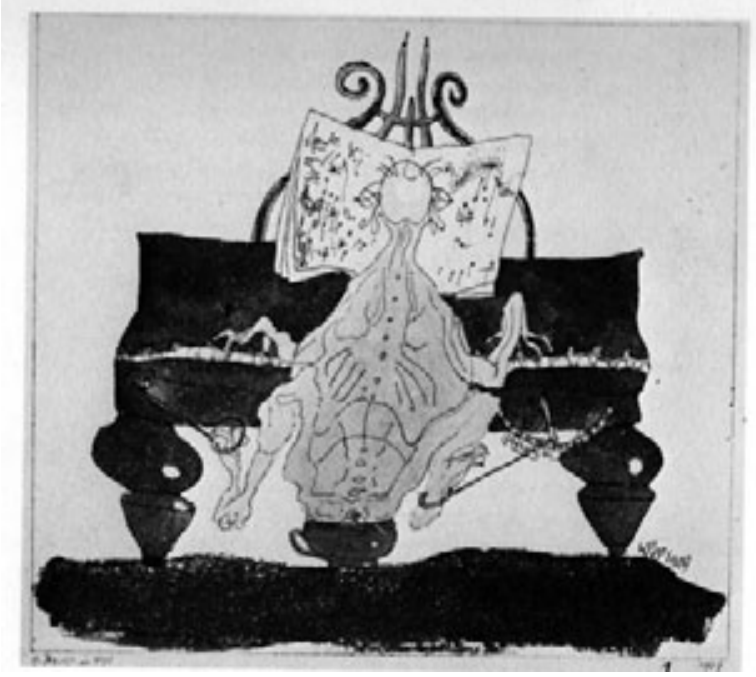

Ex.13 - Klee, Paul, O Pianista em dificuldade - Uma sátira: Caricatura de Música Moderna 1909.1. Bico de pena e aquarela, $16.5 \times 18 \mathrm{~cm}$. Felix Klee, Bern.

No sentido de demonstrar o interesse do autor pela representação conjunta da grafia musical e da pintura, apresentamos uma gravura, abstrata, realizada em 1914. Nesta obra, Klee utiliza os símbolos musicais em uma composição visual. Apesar de não estar à altura dos experimentos futuros, mesmo assim a representação demonstra a tendência do autor. Podemos observar a obra a seguir:

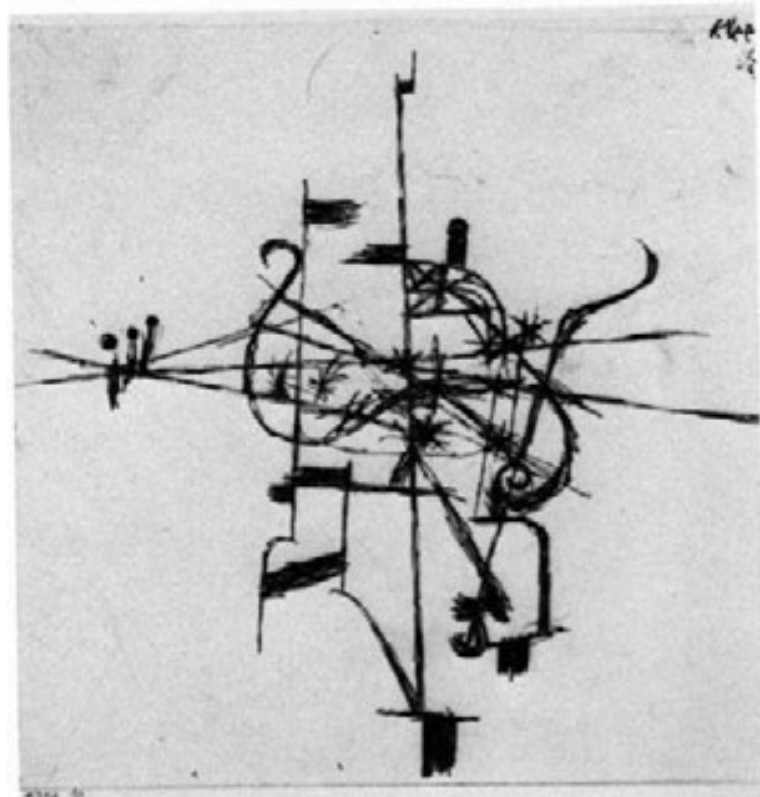

Ex. 14 - Klee, Paul, Instrumento de Música Moderna, 1914.10. Bico de pena, 17.2x16.9 - Felix Klee, Bern.

Nesta mesma época, Klee iniciava seus exercícios gráficos apoiados na linguagem abstrata. E, por meio dos estudos da forma, ele encontra um sentido para sua pesquisa. Apesar da trajetória pela representação figurativa, aos poucos os valores da figuração se tornam relativizados, na medida em que os elementos simbólicos da escritura musical invadem o universo pictórico, revelando uma nova iconicidade, ainda assim pictórica, para os elementos que são modos de representação do movimento. Há um trabalho realizado entre 1908 e 1909, desta etapa de desenvolvimento criativo que representa visualmente a idéia de movimento. Desenhando com a fermata é o nome desta obra que podemos ver a seguir:

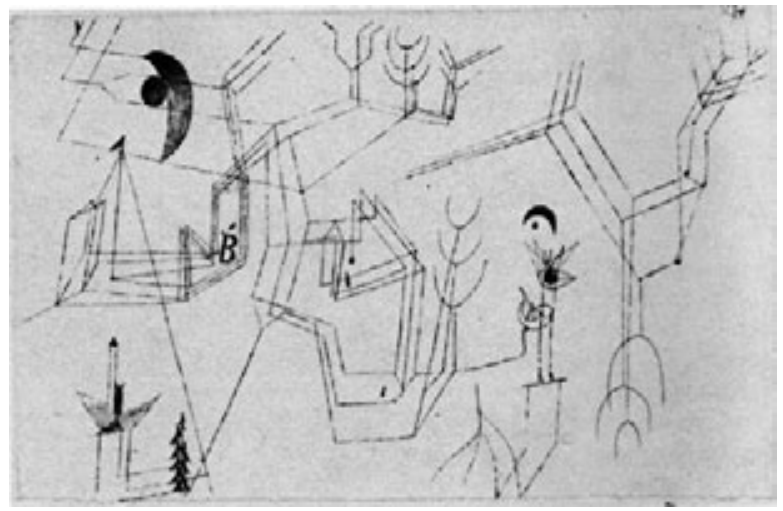

Ex.15 - Paul Klee, Desenhando com a fermata, 1918.209. Bico de pena, 15.9×24.3 - Paul Klee Foundation, Kunstmuseum, Bern.

Segundo KAGAN, na obra Art and Music, esta obra está relacionada ao "Scherzo" e emprega elementos formais abstratos - três linhas paralelas - que parecem desenvolver o movimento de uma linha melódica composta de acordes com três notas. As linhas descrevem um movimento no plano do quadro e criam a idéia espacial. 
0 "Scherzo" é um forma musical cujo nome que significa jogo, brincadeira. Geralmente, é uma composição ligeira e breve. Na sua obra, Klee caracteriza o "Scherzo", ou seja, as formas ligeiras e breves, por meio do emprego de segmentos de retas que mudam de rumo e criam formando 0 ambiente onde os jogos podem ocorrer. A fermata é outro elemento da música que está representada nesta cena.

Como elemento musical, a fermata é um símbolo que, ao ser empregado em uma obra, autoriza o intérprete a determinar o tempo de duração da nota sobre a qual o símbolo está representado. Ela determina o tempo, a espera. Nesta gravura, a fermata encontra-se no alto à esquerda e interrompe o caminho já iniciado pelas três retas, significando que a música já começara antes do espaço representado. Klee utiliza o símbolo da fermata como Ihe convém. Modifica sua posição para dar outro significado: um olho que espreita, ou utilizaa como elemento que encerra as trajetórias das retas paralelas. Esta noção de espreita está novamente presente no ponto áureo do quadro, no quadrante direito inferior, para onde segue o conjunto de três linhas que percorreram o quadro. Neste ponto áureo encontra-se uma imagem, um olho com pernas ou, quem sabe, uma brincadeira, ou pássaro, enfim, um personagem fictício com duas longas pernas e dedinhos. Nesta figura encantadora, o espírito lúdico da obra está em evidência.

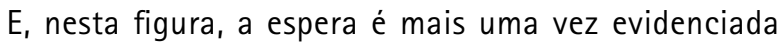
pela fermata que também destaca uma parte importante da obra.

\section{4 - Aplicação da Teoria da Forma para análi- se das pinturas de Paul Klee}

Neste sub-capitulo, procuramos demonstrar as correspondências entre a Teoria da Forma elaborada por Paul Klee e sua própria obra pictórica. Em cada pintura analisada a seguir, perceberemos a preexistência de pressupostos formais do pensamento do teórico e artista. As análises serão realizadas em pinturas do período compreendido entre 1914 e 1932.

A primeira pintura, Coupoles Rouges et Blanches, de 1914, demonstra a influência da viagem de Klee à Europa e à Tunísia. Nota-se a intenção de estruturar o espaço bidimensional e deixar em evidência a estrutura da malha de construção e, ainda na figuração, encontra-se referências a imagens reconheciveis, assim como esquemas de cúpulas arquitetônicas; arremedos de janelas e portas, insinuados por retângulos de diferentes medidas; telhados insinuados por troncos de prismas, além do espaço urbanístico e do conjunto arquitetônico, revelados pelo conjunto das formas geométricas, levando ao simbolismo do título da obra.

Analisando a imagem pelos pressupostos formais concebidos na Teoria da Forma, o que vemos é o seguinte: comandam a composição as linhas verticais que se tornam diretrizes para estruturar o quadro em módulos e sub-módulos. Enquanto as verticais são referências de um arremedo de malha de construção, as nuances das diferentes cores se incumbem de insinuar as linhas horizontais, completando os 'ritmos estruturais primitivos.' $\mathrm{E}$, no centro da composição, variando do verde ao ocre, percebe-se um arremedo de subdivisão modular, como se fossem notas de um conjunto rítmico subdividindo um tempo musical. Podemos observar, na imagem a seguir, a métrica visual em correlação com o ritmo da musica:

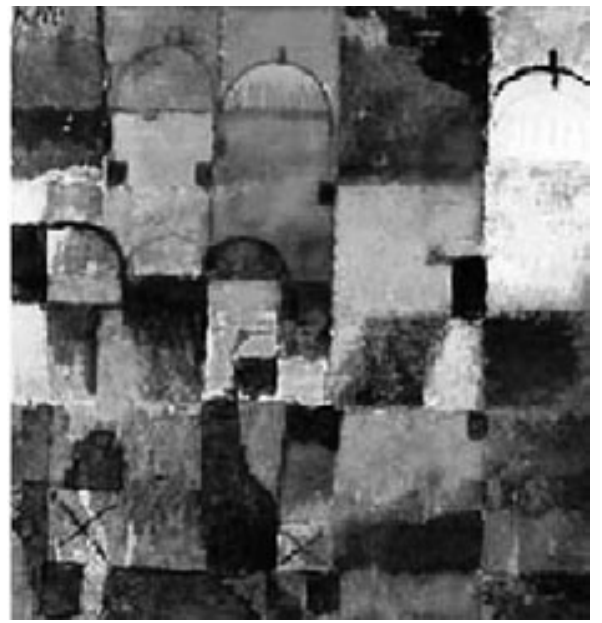

Ex.16 - Paul Klee, Cúpulas vermelha e branca, 1914. Aquarela em superfície de cor e papel japonês colado sobre cartão. 14.6 x $13.7 \mathrm{~cm}$ - Kunstsammlung Nordrhein-Westfalen, Dusseldorf

0 pintor realiza, durante este período, inúmeras obras que demonstram sua atenção para a questão formal definindo sua identidade de artista: da mente de um músico para as mãos de um pintor.

No mesmo ano de 1919, Klee realiza um trabalho mais estruturado, no qual evidencia, ainda mais, a relação da pintura com a escritura musical. Trata-se de Rhythmic Wooded Landscape, que representa uma paisagem fictícia, composta de desenhos esquemáticos de árvores dispostas em espaços que são representados pelos intermédios entre linhas horizontais. Cada espaço contido entre estas linhas horizontais é constituído a partir de um valor modular. Enquanto o menor corresponde à metade do módulo, o maior é composto de três valores modulares. Em cada um desses espaços encontram-se círculos de tamanhos diferentes, também constituídos a partir de um valor modulado e que são arremedos de cúpulas das árvores da paisagem. Há, no espaço tingido de terracota, uma imagem que insinua a silhueta de um camelo. Este espaço é composto pelos três módulos.

Apesar de representado em silhueta, o animal surge entre supostas árvores cujas diferenças de dimensões remetem ao valor de tempo do elemento musical (o ritmo). 0 título também faz referencia ao ritmo. Portanto, por meio de Rhythmic Wooded Landscape Klee representa seus conceitos teóricos como vemos a seguir: 


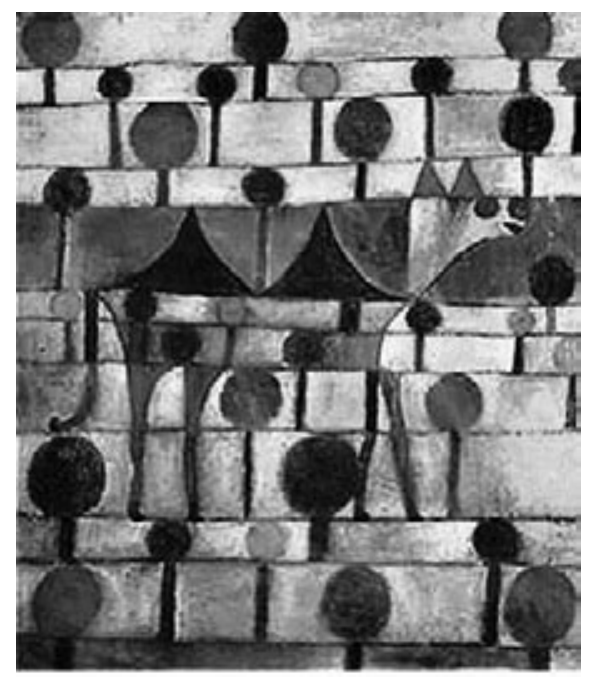

Ex. 17 - Paul Klee, Paisagem rítmica com árvores, 1920. 41, óleo em cartão , 47.4 x 29.5 -

Formerly E. Horstmann, Hamburg.

Os princípios da Teoria da Forma aparecem nesta imagem visual, similares à notação ritmica, porque na escrita musical cada valor de tempo equivale à metade de outro valor de tempo (mínimas, semínimas, colcheias etc. são referências de tempos correspondendo o próximo à metade do tempo do anterior). Na pintura, o que vemos são, também, elementos visuais, ou marcações estruturais visuais com medições variáveis.

A seguir, analisaremos a obra realizada em 1927, chamada: Flora on the Sand. Totalmente geométrica e composta de quadrados de medidas variáveis, a pintura demonstra como o pintor realiza seqüências de quadrados subdivididos, definindo módulos e sub-módulos. $E_{\text {, }}$ por meio deste artifício, Klee mantém a idéia de movimento, como também ocorre na divisão do tempo da música. No detalhe esquemático, apresentado ao lado do quadro, podemos compreender a divisão modular, como tempos da notação musical e subdivisões dos módulos quadrados, como as subdivisões dos valores de tempo das notas musicais:

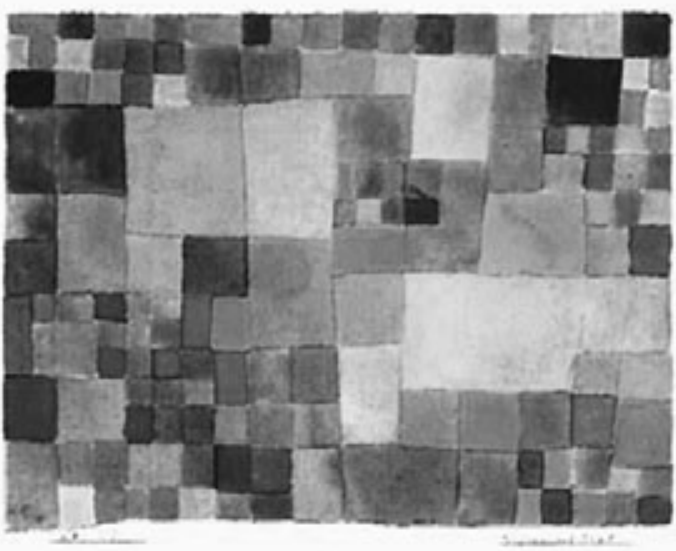

Ex. 18 - Paul Klee, Flora na areia - (1927). Aquarela sobre papel - Collection Felix Klee, Bern.
A duração de um tempo passa a ser uma unidade de medida representada pelos módulos e sub-módulos visuais. Este é um passo importante na representação futura dos quadrados mágicos.

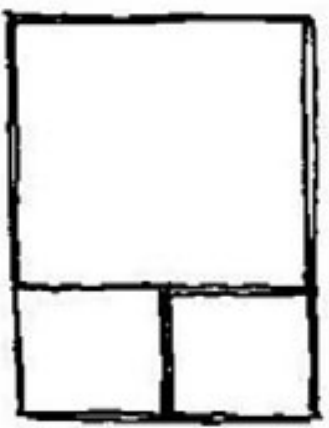

Ex.19 - Paul Klee: exemplo de esquema demonstrando os valores modulares e as subdivisões, correspondendo a um módulo na parte superior direita do quadro Flora na areia, apresentado na ilustração anterior.

Na próxima obra, encontraremos a sintese da representação da Teoria da Forma, pois, além de elaborar a estrutura primitiva (a formação dos módulos quadrados), o movimento emerge como a resposta aos seus anseios. Pela cor, Klee realiza sua intenção na aquarela chamada Alter Klang, de 1925. Podemos observar a obra a seguir:

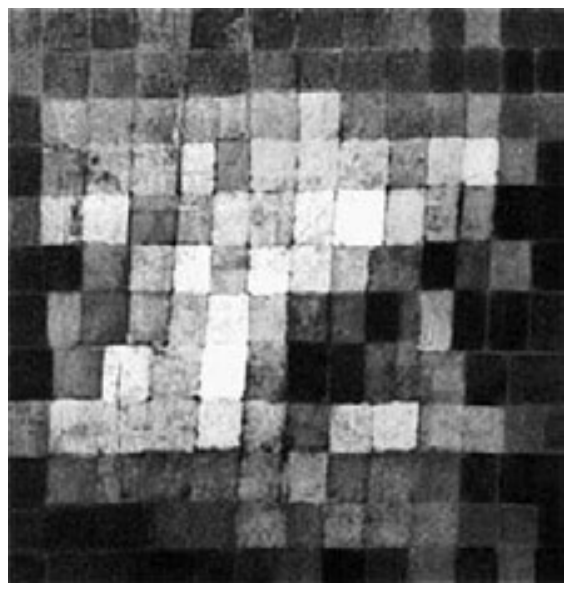

Ex.20 - Paul Klee, Música Antiga (tradução livre), 1925.236. Óleo sobre cartão, 38 x 38. - Kunstmuseum, Basel.

Klee realiza uma composição abstrata geométrica procurando transmitir a ambientação da época das velhas canções. Na obra Paul Klee: Arte and Music, Andrew Kagan comenta sobre esta obra:

Alter Klang é o espectro de evocações ascendentes que vem da obscuridade dos negros profundos e verdes concentrados nos ângulos do quadro para a serenidade dos rosas e amarelos no centro do trabalho (KAGAN,1989).

Utilizando a malha de construção com módulos constantes em uma composição inteiramente realizada pela cor, Alter Klang é planar e, ao mesmo tempo, as cores claras estão sobrepostas a um fundo de cor escura. Cada cor é 
um módulo signo cujo conjunto tem a intenção de remeter ao antigo tempo das canções harmônicas. Também, a partir destes mesmos módulos, nota-se movimento e ritmo onde cor e módulos definem o movimento dos quadrados mágicos. Cada módulo tem o valor de signo, pela cor representada, mas também pode ser uma nota relacionada ao módulo seguinte, intuindo uma linha pictórica estruturada, remetendo à idéia de movimento da linha musical.

\section{Com Alter Klang, Klee constitui:}

[...] uma verdadeira estrutura como no compasso musical, a partir da qual ele pode compor com as cores [...]. Alter Klang é um paradigma de construção puramente pictórica, e a definição das possibilidades que a temática da cor contém. (KAGAN,1989).

Outro trabalho igualmente importante no sentido de demonstrar a relação entre a música e as artes visuais foi realizado em 1930: Three-part Time with the Quartered e um trabalho utilizando a tinta guache. Esta obra apresenta uma proposta ainda mais evidente da utilização dos módulos de cor que remetem aos tempos musicais. Não se encontram referências reais ou figurativas, pois a imagem dispensa a representação de um objeto real ou existente. Three-part Time with the Quartered, pelo contrário, representa um elemento da música que está identificado no título da obra. Three-part Time quer dizer: tempo em três partes, tem correspondência com o compasso ternário. Vamos observar a obra a sequir:

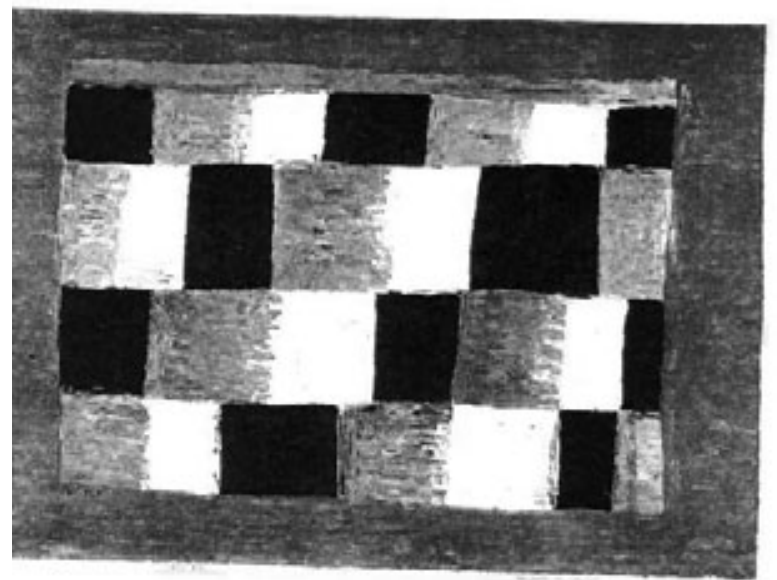

Ex. 21 - Paul Klee, Divisão a Três Tempos. 1930. Guache, 44.5 × 61.2 - Marlborough Fine Art (London) Ltd.

Klee utiliza nesta obra um esquema com alternância para representar a grafia musical do compasso ternário. 0 primeiro tempo é identificado pela cor preta; o segundo pela cor cinza e o terceiro pelo branco. Estes elementos se repetem em várias seqüências de pretos/cinzas/brancos. Na composição musical, o compasso determina o ritmo. Assim também ocorre na representação desta pintura.

Na obra, Klee sintetiza a marcação rítmica de uma composição em compasso ternário - o primeiro tempo mais forte; o segundo menos forte; e o terceiro mais fraco. Representando cada tempo em preto (mais forte), cinza (menos forte) e branco (mais fraco) ele induz à representação das nuances de marcação dos tempos na música.
Pelos quadrados mágicos, Paul Klee realiza as representações harmônicas. Mas também elabora estudos de transparências de cores e superposições para representar a tridimensionalidade: a polifonia.

Ao superpor os elementos modulares, Klee encontra a maneira de representar uma obra polifônica (MARÇAL,2009). 0 modo de resolver a questão é chamado por ele de cor polifônica.

A polifonia constitui-se em um processo complexo de composição musical no qual cada grupo de instrumentos realiza, separadamente, seqüências de notas que não corresponde à linha melódica e sim a uma parte desta. Quando os conjuntos instrumentais realizam as seqüências ao mesmo tempo, em conjunto, a melodia surge do somatório de todas estas partes.

Nas experiências de Klee, a polifonia emerge dos planos superpostos de cores transparentes. A superposição das cores transparentes permite vislumbrar o somatório de todas as cores e o resultado que é a forma definitiva. Em termos visuais, o somatório das cores também vai representar um elemento que surge do conjunto de todas as cores.

Para fins didáticos, Klee apresenta os desenhos que chama de Three-part Polyphony.

Nestes trabalhos demonstra a rede que se forma quando estruturas se cruzam e determinam uma nova estrutura que é o somatório das partes. Ele apresenta três grupos de elementos visuais: dois quadrados vermelhos, hachuras horizontais e hachuras verticais. Estes modelos apresentam-se à direita do quadro.

À esquerda vemos os três motivos superpostos. Nesta superposição nota-se um padrão composto dos três elementos. Assim, Klee encontra o meio de representar visualmente o efeito produzido pelos conjuntos instrumentais da música. Podemos observar o estudo a seguir:

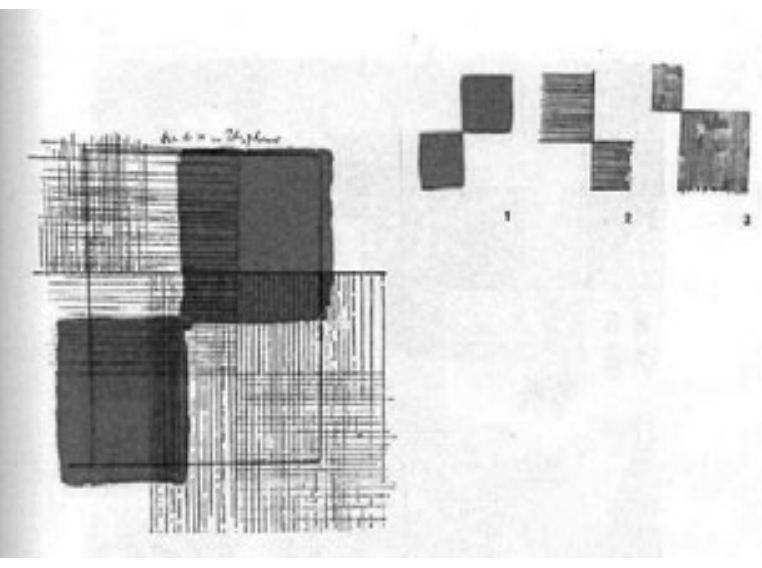

Ex. 22 - Paul Klee, Polifonia a Três Partes, illustração nas anotações de Klee's para cursos da Bauhaus (1921-22). Paul Klee Foundation, Kunstmuseum, Bern. 
As experiências com as cores realizadas por Paul Klee a partir de 1930 demonstram sua busca pela representação da profundidade. Para conseguir o recurso que necessita, ele passa a utilizar seqüências de pontos como o meio visual de representar a polifonia. Desta forma, torna-se possível cobrir a superfície do quadro com uma cor, superpondo outras sem que nenhuma delas fique encoberta totalmente, solucionando a questão da profundidade e da superposição de panos de cor.

Em 1932 Klee realiza a obra Polyphony como demonstração clara de aplicação dos estudos teóricos e práticos. $\mathrm{Na}$ superfície do quadro, Klee realiza uma composição com retângulos de cor (estrutura de módulos) e aplica conjuntos de cores em forma de pequenos pontos. Neste sistema encontram-se vários conjuntos de cores superpostas formando uma unidade e que sugere à Klee a polifonia. $\mathrm{Na}$ pintura a seguir é possível observar as superposições dos pontos e as transparências.

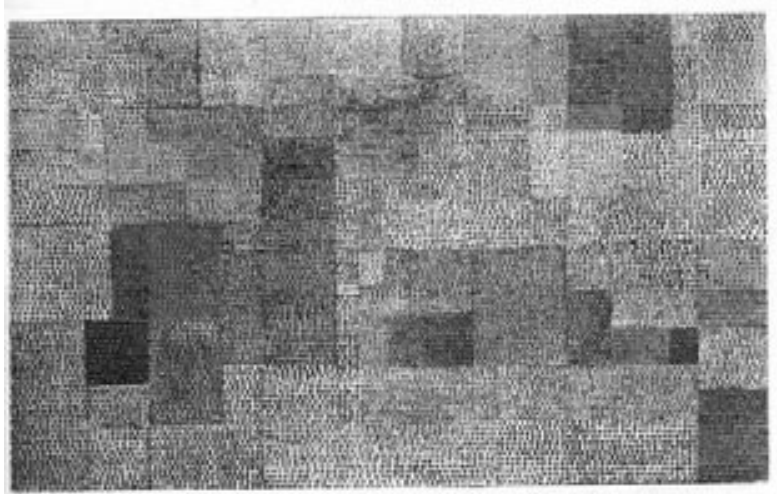

Ex. 23 - Paul Klee, Polifonia, 1932-3=273; têmpera em tela, 66.5 x $106 \mathrm{~cm}$. Emanuel Hoffmann Foundation, Kunstmuseum, Basel.

Em suma, as proposições teóricas de Paul Klee evoluíram ao ponto de alcançar seu propósito: a criação de um sistema visual que representasse o movimento, o ritmo, a linha melódica, definido pelas seqüências de notas que se tornam módulos; pelas seqüências de compassos da linha melódica que se tornam divisões do espaço; seguindo valores mensuráveis na linha melódica que se tornam divisão modular no espaço visual. Por fim, realiza a notação da polifonia, por meio da profundidade que consegue com as transparências obtidas pelas superposições de cores da aquarela e do pontilhismo.

\section{Conclusão:}

0 estudo realizado por Paul Klee com a intenção de demonstrar a relação existente entre a linguagem da música e da pintura é bem mais abrangente e detalhado do que fomos capazes de apresentar neste artigo. Alguns segmentos representando a Fuga, ou as Variações musicais nem foram sequer nomeados neste trabalho por limitação de espaço.

Mesmo assim, consideramos que o esboço do assunto tornou possivel demonstrar o propósito do pintor ao desenvolver uma teoria destinada ao aprimoramento da linguagem visual que pudesse solucionar para as artes visuais as dificuldades de representação do movimento e da profundidade.

Os estudos de Klee resultaram numa elaborada Teoria da Forma, mais tarde organizada por Moholy-Nagly, também professor da Bauhaus e que servem, ainda hoje, para fundamentar a didática da Metodologia Visual, sendo útil para a formação de designers e comunicadores visuais das Escolas mais tradicionais.

Utilizada na atualidade sem que se cogite a origem dos ensinamentos: a representação visual do movimento pela relação estabelecida com a escritura musical, o sistema adotado tem o sentido de revelar pressupostos formais para a representação. Por ter sido editada durante a estadia de Klee na Bauhaus e por ser ele considerado até os dias de hoje como um dos principais professores daquela Instituição, a teoria que trouxe para as artes visuais as noções de modulação, ritmo, psicodinâmica das cores (não apresentado neste artigo) é, na atualidade, modelo da Boa Forma e, por este motivo, é comumente adotada no ensino do design e da comunicação visual como modelo pressuposto de qualidade estética.

Sendo assim, o valor da obra que relaciona a linguagem musical com a visual sequer é explicitado, utilizando-se apenas a tendência da criação artística por meios pressupostos visuais.

No entanto, pelo fato de que nunca houve, em nenhum tempo, um artista - pintor e músico - que tenha realizado um trabalho tão aprofundado, teórico e pictórico, procurando demonstrar os paralelismos entre as linguagens das artes, 0 pequeno demonstrativo deste artigo tem o valor de reviver sua obra e deixar, para mais adiante, o interesse despertado para maiores revelações a respeito de seus questionamentos. 


\section{Referências:}

ARNHEIM, R. Arte e Percepção Visual. Uma Psicologia da Visão Criadora. SP, Edusp, 1986.

DROSTE, M. Bauhaus 1919-1933, Berlim, Benedikt Taschen, 1994.

GEELHAAR, C. Paul Klee et le Bauhaus. Neuchâtel Iles e Calendes, 1972.

KANDINSKY, W. Curso da Bauhaus. SP. Martins Fontes, 1987.

. Do Espiritual na Arte. SP. Martins Fontes, 1990.

.Ponto, Linha, Plano. RJ. Edições 70, 1989

KAGAN, A. Paul Klee, Art \& Music. NY. Cornell University Press, Ithaca and London, 1989.

KAMPER, D. O Corpo. Trad. Centro Interdisciplinar de Semiótica da Cultura e da Mídia. http://geccom.incubadora.fapesp. $\mathrm{br} /$ portal/referencias/textos/kamper/corpokamper.pdf. (visit.2008).

KLEE, P. La Pensée Créatice. Écrits sur L'Art / 1. Textes recueillis et annotés par Jurg Spiller. Paris. Dessais et Tolra, 1973. .Paul Klee und Die Musik. Frankfurt. Schirn- Kunsthalle Frankfurt, 1986.

Diários. SP. Martins Fontes, 1990.

Teoria del Arte Moderno. Buenos Aires. Calden,1979.

MARÇAL, R. Ekphrasis em música: os Quadrados Mágicos de Paul Klee na Sonata para

violão solo de Leo Brouwer. Per Musi, Belo Horizonte. n.19, 2009, p. 47-62.

TARNAS, R. A Epopéia do Pensamento Ocidental. RJ. Bertrand Brasil, 2008.

WICK, R. Pedagogia da Bauhaus. SP. Martins Fontes, 1990.

\section{Leitura Recomendada:}

. Intuição e Intelecto na Arte. SP. Martins Fontes, 1989.

AMARAL, A. Projeto Construtivo Brasileiro na Arte: 1950 - 1962. SP. Mec, Funarte, Museu de Arte Moderna, Secretaria da

Cultura, Ciência e Tecnologia do Estado de São Paulo, 1977.

ARGAN, G. C. Arte Moderna. Do lluminismo aos Movimentos Contemporâneos. SP. Companhia das Letras, 1993.

CALABRESE, O. A Linguagem da Arte. RJ, Ed. Globo, 1987.

CHEVALIER, D. Klee. Paris. Librairie Paris, Flammarion, 1971.

CLEAVER, D.Ct EDDINS, J. Art and Music. An Introduction NY. Harcourt Brace Jovanovich Inc., 1977.

CUNHA, C. e-dicionário org: Carlos Ceia - Duplo. http://www2.fcsh.unl.pt/edtl/verbetes/D/duplo.htm.

GOOHMANN, W.I. Paul Klee. NY. Harry N. Abrams Inc. Publishers, s/d.

HARNONCOURT,N.O Discurso dos Sons. Caminhos para uma Nova Compreensão Musical. 2a ed. RJ. Jorge Zahar, 1990.

HÖRMANN, H. Psicología del Lenguaje. Biblioteca Románica Hispánica. Madrid. Editorial Gredos,1973.

SIQUEIRA, B. Filosofia e Música. s/e s/l 1983. Música Força Movimento. RJ. Uirapuru, 1983.

SPANUDIS, T. Construtivistas Brasileiros. RJ. s/e, s/d.

STANGOS, N. Conceitos da Arte Moderna. RJ. Jorge Zahar, 1991.

TORRES-GARCIA, J. Universalismo Construtivo. Vol.2. Madrid. Editorial Alianza, 1984.

Rosana Costa Ramalho de Castro é pós-doutoranda do programa de pós-graduação em Letras da UFF, possui doutorado em História pela UFF (2004) e mestrado em Artes Visuais pela UFRJ (1995). É professora da Universidade Federal do Rio de Janeiro desde 1981 e atualmente ocupa a função de Professor Adjunto. É professora credenciada do Programa de PósGraduação em Ciência da Arte- UFF e do Programa de Pós-Graduação em Artes Visuais - UFRJ. É membro da comissão de elaboração do Programa de Pós-Graduação em Design- UFRJ. Dedica-se à pesquisa sobre: semiótica aplicada; representações culturais; design para a sustentabilidade, comunicação visual, atuando principalmente nas áreas de sociologia cultural e da imagem, semiótica cultural e visual, design e comunicação visual e semiótica do design. É membro da Latin American Studies Association - Pitt/edu. 